\title{
Digital platforms in supporting ICTD research collaboration: A case study from South Africa
}

\author{
Samwel Dick Mwapwele \\ Department of Information Systems, University of South \\ Africa \\ Samwel.mwapwele@hotmail.com
}

\author{
Judy van Biljon \\ Department of Information Systems, University of South \\ Africa \\ vbiljja@unisa.ac.za
}

\begin{abstract}
Given the resource constraints many researchers in developing countries face, digital platforms are an important resource in supporting intra and inter-university as well as international research collaborations. The design of digital platforms for supporting research collaboration in the field of Information and Communication Technology and Development (ICTD) pose a complex problem since the target group is diverse and dynamic. This study reports on an investigation into the use and usefulness of a digital platform for ICTD research collaboration in South Africa. The study uses interpretivism as a philosophy with the theory of deferred action (TDA) as a theoretical lens and a knowledge repository (digital platform) as the IT artefact to be evaluated in terms of use and usefulness. The sequential mixed-method data capturing approach involved the survey method with open-ended questionnaires to capture user's input and Google Analytics to capture actual use. The findings on the users' demographics and access patterns provide insight into the diverse user group and some counterintuitive insights on the origin of many of the users. The research contributes to the body of knowledge by providing evidence-based insights on the use and usefulness of a digital platform for research collaboration in the field of ICTD. The application of TDA to theorize the findings provides a unique theoretical contribution as well as some practical recommendations on improving the usefulness of knowledge repositories for collaborating and sharing research knowledge.
\end{abstract}

\section{CCS CONCEPTS}

- Human-Computer Interaction (HCI); • Collaborative and social computing; • Information Systems;

\section{KEYWORDS}

Research collaboration, usefulness, South Africa development informatics, research community

ACM Reference Format:

Samwel Dick Mwapwele and Judy van Biljon. 2021. Digital platforms in supporting ICTD research collaboration: A case study from South Africa. In 3rd African Human-Computer Interaction Conference (AfriCHI 2021), March

Permission to make digital or hard copies of all or part of this work for personal or classroom use is granted without fee provided that copies are not made or distributed for profit or commercial advantage and that copies bear this notice and the full citation on the first page. Copyrights for components of this work owned by others than ACM must be honored. Abstracting with credit is permitted. To copy otherwise, or republish, to post on servers or to redistribute to lists, requires prior specific permission and/or a fee. Request permissions from permissions@acm.org.

AfriCHI 2021, March 08-12, 2021, Maputo, Mozambique

(c) 2021 Association for Computing Machinery.

ACM ISBN 978-1-4503-8869-6/21/03 \$ \$15.00

https://doi.org/10.1145/3448696.3448714
08-12, 2021, Maputo, Mozambique. ACM, New York, NY, USA, 6 pages. https://doi.org/10.1145/3448696.3448714

\section{INTRODUCTION}

Research collaboration is defined as the process whereby two or more individuals collectively address issues with the outcome being scientific knowledge production [1]. Research collaborations have different facets including intra-universities, inter-universities, organizations, national and international level [2] where the collaborations accommodate the collective interests of the researchers involved [3]. To improve their collaboration, community members and network stakeholders require a process of inter-communal sense-making $[4,5]$ since research communities co-exist in a complex context of relations and interactions with other communities, the interactions need to be supported by purposively designed multi-layered technical infrastructure [6]. For example, a digital platform defined as "a proprietary or open modular layered technological architecture that support efficient development of innovative derivatives, which are embedded in a business or social context" [7, p. 2]. These platforms facilitate knowledge transfer for research collaboration by concentrating on support services and reducing the time to acquire such services [8]. Freshwater, Sherwood and Drury [9] argue that the use of Information and Communication Technologies (ICTs) have fostered not only the exchange of information but it has also supported the creation and dissemination of knowledge. Examples of digital platforms include open knowledge repositories, applications and social networking tools. The terms digital platforms and open knowledge repository (OKR) are used interchangeably from this point on. The open knowledge repository used as the case study is an ICTD-X knowledge repository developed to assist with social interactions among researchers in South Africa.

One approach to measuring the effectiveness of research collaborations, and therefore development, is through research outputs; publications, in books, conferences and journals [9]. Jiao and Corser [3] contend that the other approach is acknowledging the networks built through research cooperation and collaboration. The distinction between the two approaches is that the former focuses on tangible and objective outcomes of research collaboration as measured by bibliometrics while the latter is centred on the subjective, tacit knowledge and unrecognized benefits as better measured by altmetrics [10] - if at all quantitatively measurable.

Castells [11] contends that the use of web 2.0 and 3.0 has assisted in the advancement of societies through networks that are developed by community engagement. This drive to digitization has been exacerbated by the 4IR as accelerated by the COVID-19 pandemic 
[12]. Not only do digital platforms reduce the time and cost in communicating and travelling [9], but the use of knowledge repositories offers researchers a space to connect and discover information on upcoming events. Despite these potential benefits, the adoption and use of digital platforms for supporting research collaboration has not received much research attention and evidence-based design criteria towards supporting the adoption of digital collaboration platforms in the field of ICTD [13] and informal learning [14] are lacking. The challenge is exacerbated by a lack of publications on knowledge repositories [15]. Therefore, we investigate the adoption and usefulness of a digital platform for research collaboration. Following earlier discussions on adoption [13, 15], we define adoption in this research as the act of regularly engaging with the digital platform to acquire information. This research contributes to the body of theoretical knowledge by the application of the theory of deferred action (TDA) to understand the use and usefulness of a digital platform for research collaboration by investigating the South African ICTD researchers' use of a digital platform to share and transfer knowledge and that also leads to some practical recommendations.

The second (next) section discusses the literature on OKR usability. The third section provides insight into the methodology, results and findings respectively. The paper concludes with the study's limitations, contributions and suggestions for future work.

\section{INFORMING LITERATURE}

The theory of deferred action (TDA) was developed to facilitate the design of IT artefacts intended for use by individuals and organizations by Nandish Patel [16]. TDA is a theory developed for Information Systems (IS) and targeting complex adaptive systems that have emergent behaviours [16] far from those of the environment and thus require adaptation. TDA focuses on the design of an IT artefact that will be used by individuals who exist in a society bound to interact and change over time. The main intention of using the theory of deferred action was thus to understand the use and usefulness of the ICTD-X knowledge repository taking into account the intentions of the developers and their audience. The theory intends to assess the effect the social systems have on the artefact before, during and after the design. Further, the theory intended to capture the knowledge gained in the process and how it has affected the advancement of the artefact [17].

The theory of deferred action guides the capturing of the design and actions [16] that are involved in the development of an ICT artefact [17] such as a knowledge repository. The theory incorporates three fundamental concepts, namely, planned actions, emergent actions and deferred actions which can be explained as follows:

- Planned actions: Any knowledge repository developed follows a rational design plan on what should be included, technology to use and the intended audience among other issues. Knowledge repository developers have to include specific design and usability concepts in meeting the objectives of the knowledge repository.

- Emergent actions: Once the knowledge repository goes 'live', neither the knowledge repository developers nor the owners have control over visitors but can monitor and investigate.
Any of the knowledge repository users including developers, owners and visitors will notice opportunities, issues and problems in the knowledge repository, in terms of additional features, bugs, errors and omissions, that are reported to knowledge repository administrators and developers for rectification.

- Deferred actions: Certain features and requirements that were not included in the initial plan might be seen as important as time progresses. The knowledge repository will thus undergo changes which are referred to as deferred actions. The idea of introducing changes while the knowledge repository is live not only produces the deferred actions but also assists in either alignment to the planned action or extension based on emergent actions.

These changes are necessitated by the demand from visitors and influenced by technology advancement. Thus, the theory of deferred action accommodates changes in technology based on social systems and human interactions in the course of achieving the intended technology objectives [17]. The social system is termed to be emergent as it changes over time creating unpredictable actions that require regular updates on the knowledge repository and in turn demand deferred actions. The actions of updating a knowledge repository to accommodate societal demand and technology advancement can be termed as deferred action. The value that TDA provides in research is to allow for a deeper understanding and theorization of the design of the knowledge repository and the actions of the individuals in the social system towards updating the knowledge repository to meet the needs of the users.

\section{METHODOLOGY}

The research follows a mixed-method approach and investigates the ICTD-X knowledge repository, www.ict4dsa.com, interactions among ICTD-X members, knowledge repository administrators and knowledge repository visitors. The interaction among ICTD-X members thus provides the context of this research. This community of South African ICTD researchers is of interest because there is a documented lack of research collaboration among researchers in African countries [18].

The collective understanding of the ICTD-X knowledge repository follows the interpretive philosophy by acquiring different ICTD members views of the knowledge repository, the use of the knowledge repository and contribution of relevant items to add to the knowledge repository. Our investigation of the knowledge repository activities is informed by the objective of the knowledge repository and reflecting on whether it [the knowledge repository] had achieved its purpose of sharing knowledge and supporting research collaboration in the South African ICTD community. We do this by considering Google Analytics usage over 19 months between May 2017 and December 2018.

The discussion on knowledge repository planning, implementation and the initial observations and reflecting are documented in previous publications $[13,15,19]$. The research uses a sequential mixed-methods approach in that quantitative and qualitative method for collecting and analysing data are applied [20]. The research began by sending a questionnaire to ICTD-X members to request them to add information on the knowledge repository and 
provide quantitative and qualitative responses regarding the site. The quantitative data were collected on the knowledge repository using Google Analytics (as a tool) and analyzed using descriptive statistics (frequency distributions).

The self-administered open-ended questionnaire was sent to 60 ICTD researchers. The ICTD researchers were identified after doing a Google Scholar search using the keywords South Africa and (development informatics or ICTD) based on publications done in three years, from 2014 to 2016, in conferences and journals.

\section{RESULTS}

The results from the survey with ICTD researchers will now be presented followed by the results from the Google analytics on ICTD-X. We received 16 responses from ICTD researchers $(27 \%$ response rate) that were analyzed using directed content analysis as advocated by [21]. The theory of deferred action informed the use of a deductive approach. Additionally, the Microsoft Word document (sent as an attachment on the email) required researchers to include suggestions for:

- Seminal paper. These will be research papers written by other researchers that are relevant to the ICTD field and relevant for young researchers to engage with. Each ICTD member was requested to add details of up to a total of five publications in the form of conference, journal or books (also book chapters).

- Individual research paper. The ICTD members were asked to provide details of research they have conducted that are published in peer-reviewed conferences, journal and books.

- Recommendations for researchers. Researchers were asked to suggest other ICTD researchers that are not ICTD members for inclusion on the knowledge repository.

- Recommendations for practitioners. Lastly, ICTD members suggested practitioners who operate and are interested in ICTD but not affiliated to universities that should be added on the knowledge repository.

\section{FINDINGS}

We now unpack the results in terms of the theory of deferred action. The low response rate $(27 \%)$ was to be expected given the diverse community, the heavy demands on ICTD researchers in South Africa including their time (lecturing, research duties, community engagement, academic citizenship, and family demands) and the many competing digital platforms.

In response to the request to provide seminal papers in the field of ICTD, the respondents included a minimum of 3 and a maximum of 6 publications. The publications represented researchers in South Africa and some outside the country. There was some repetition in the papers, this suggests that the ICTD researchers have some agreement in terms of the seminal papers.

Researchers suggested ICTD researchers from their universities and also from other South African universities. Notably, the request pertained only to South African researchers. In some cases, researchers suggested their masters, $\mathrm{PhD}$ and postdoctoral fellows. The suggestions on students included those who are university alumni's. ICTD members suggested individuals in research labs (for example one of the RLabs champions was referred by three ICTD members), organizations (such as Association for Progressive Communications (APC)) and independent researchers. However, there was limited information provided about recommending a practitioner besides those from RLabs, APC and the three independent researchers.

Concerning knowledge repository visitation information from Google Analytics, we found out that 734 people had visited the knowledge repository in the period between 8th of May 2017 and Dec 2018. The 734 visitors included $628(86 \%)$ of new visitors and $14 \%$ of returning visitors. Google Analytics identified a knowledge repository visitor by their IP address and allocating the status of returning visitor if the same IP address has accessed the knowledge repository before. Observing knowledge repository visitations by months we realize that the lowest number of visitation was five, January 2018, and the highest being 198, August 2018.

The period was selected to follow the completion of the first cycle of knowledge repository upgrade in May 2017 that lead to a revised knowledge repository in June 2017. The date for Dec 2018 is when data analysis for the second cycle was completed. The demographic information on the knowledge repository visitation is now represented by age, gender, and language. The detailed information comprises of the frequency of visitors, events that attract visitors, the technology used to access the knowledge repository and visited pages.

Age: Knowledge repository visitors age was distributed in groups of four with a range of seven years between them. The lowest group was visitors aged 18-24 that comprised of $16 \%$ followed by 25-34 that constituted $35 \%$ and being the largest. The next group was $35-44$ with $32 \%$, the second-largest, and lastly, $45-54$ years old with $17 \%$.

Gender: Males dominated with 59\% visitation on the knowledge repository and females accounting for $41 \%$.

Language: Concerning language, the United States English was the most used with 372 (57.5\%) visitors followed by Brazilian Portuguese with 99 (15\%). In the third place was French with 36 (5.4\%) followed by British English with 34 (5.1\%) in the fourth position and South African English in the fifth. The knowledge repository does not have an option for users to change the language. A large number of Portuguese visitors emerged as an action which triggered the need (deferred action) to consider adding a feature, "change the language".

\subsection{Location of knowledge repository visitors}

The knowledge repository was aimed at South African researchers with intentions to broaden the target group to African researchers and the rest of the world later. Interestingly the information and knowledge demand from the United States of America (149) exceeded that from South Africa (132) as shown in Figure 1. The most active country from the Sub-Saharan African is Angola (position 19). Therefore, the interest from African countries was low in comparison to that from other continents. The mismatch between the expected visitors (South Africa and other African countries) and the geographic origins of the actual visitors emerged as an action that raises questions about the knowledge repository's audience. The deferred action (changes appearing from emergent actions and not included in the planned actions) is to be more inclusive in 


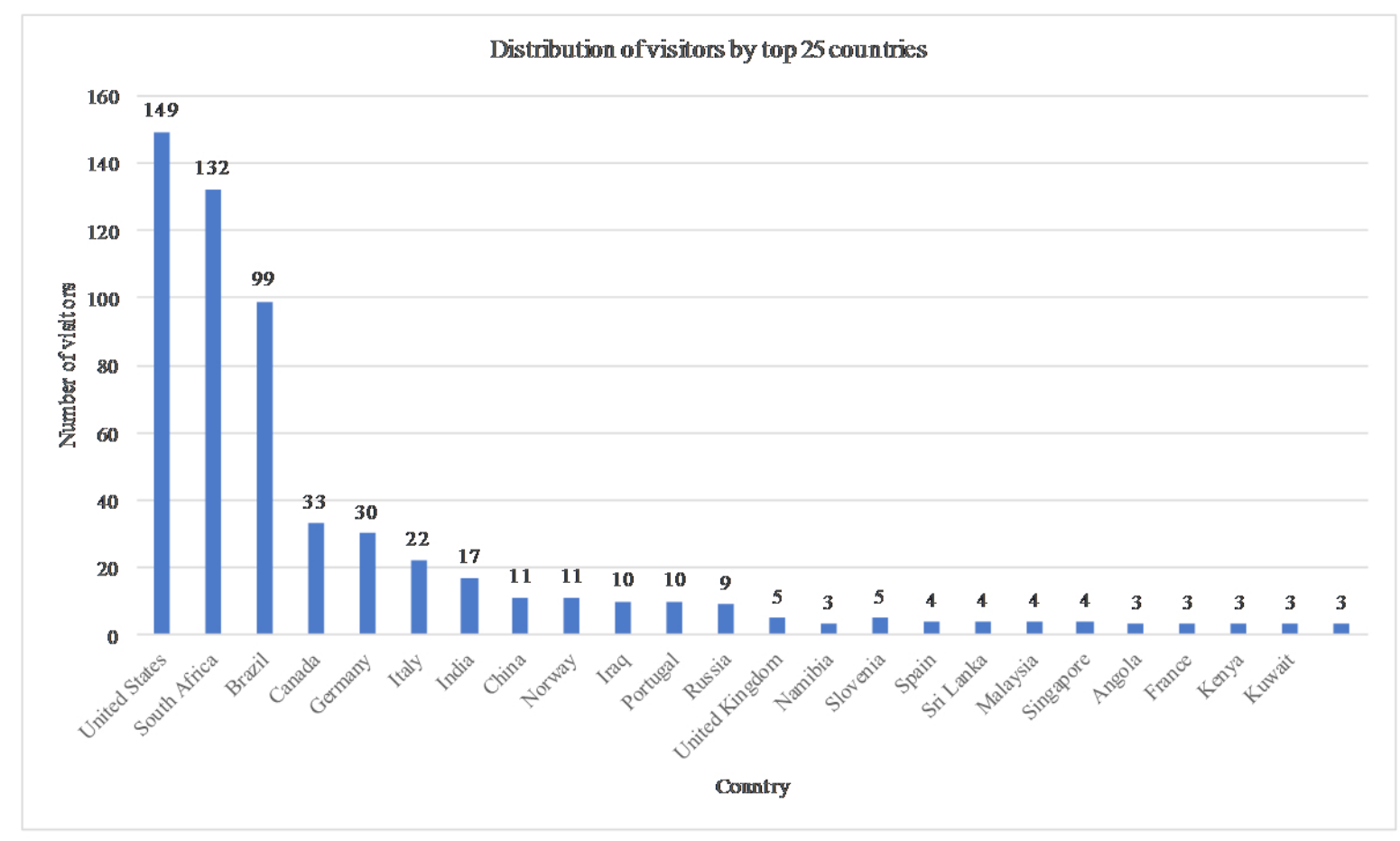

Figure 1: Countries where knowledge repository visitors reside.

Table 1: Important ICTD events occurring in Sub-Saharan Africa.

\begin{tabular}{llllll}
\hline & Event & Full-paper submission deadline & Frequency & Conference attendance dates & Frequency \\
\hline 1 & IDIA 2018 & 15/30 March 2018 & 31 & 23-24 August 2018 & 198 \\
2 & M4D & 30 Jun 2018 & 11 & 15-16 Nov 2018 & 55 \\
3 & IFIP WG 9.4 & 3 Sept to 4 Oct 2018 & 60 & 1-3 May 2019 & \\
4 & IST-Africa & 21 Dec 2018 & 51 & 8-10 May 2019 & \\
\hline
\end{tabular}

terms of language and include features that cater to an international audience such as a language translation feature.

\subsection{Events that lead to most visitors on the knowledge repository}

To understand the visitors' frequency patterns, we engaged with important dates regarding ICTD events. We selected four prominent conferences and present the summary of frequencies accordingly (see Table 1).

We noticed that in months preceding a conference submission deadline the number of knowledge repository visitors is in the tens and in the exact month where the submission is due the number rises as evidenced during International federation of information processing (IFIP) workgroup 9.4 and IST-Africa. Additionally, the months were conferences were held in Sub-Saharan Africa such as the international development informatics association (IDIA) in South Africa and mobile for development (M4D) in Uganda the number of visitors increases substantially with the former reaching 198 and the later 55 visitors. The frequency for IFIP WG9.4 and
IST-Africa conference attendance dates are not included as they fall out of the scope of the data captured.

\subsection{Technologies used to access the knowledge repository}

The Google Analytics information shows that $94 \%$ of knowledge repository visitors used desktops, about $48 \%$ used mobiles and only $1 \%$ uses tablets. These results are not mutually exclusive. For the past few years, companies that develop applications such as the browser and operating systems (OS) have designed their software's for desktop, mobile and tablets to operate more or less in the same manner. This emergent action is caused by the increase in numbers of people using mobile technologies such as smartphones and tablets. The emergent action observed is that Google Analytics might not be differentiating between a Windows 8 and Windows 10 OS found in a tablet, laptop and that found in a desktop computer because the Windows OS uses the same OS for tablets, laptops, smartphones and desktop computers. We present the operating systems used to access the knowledge repository in Figure 2 


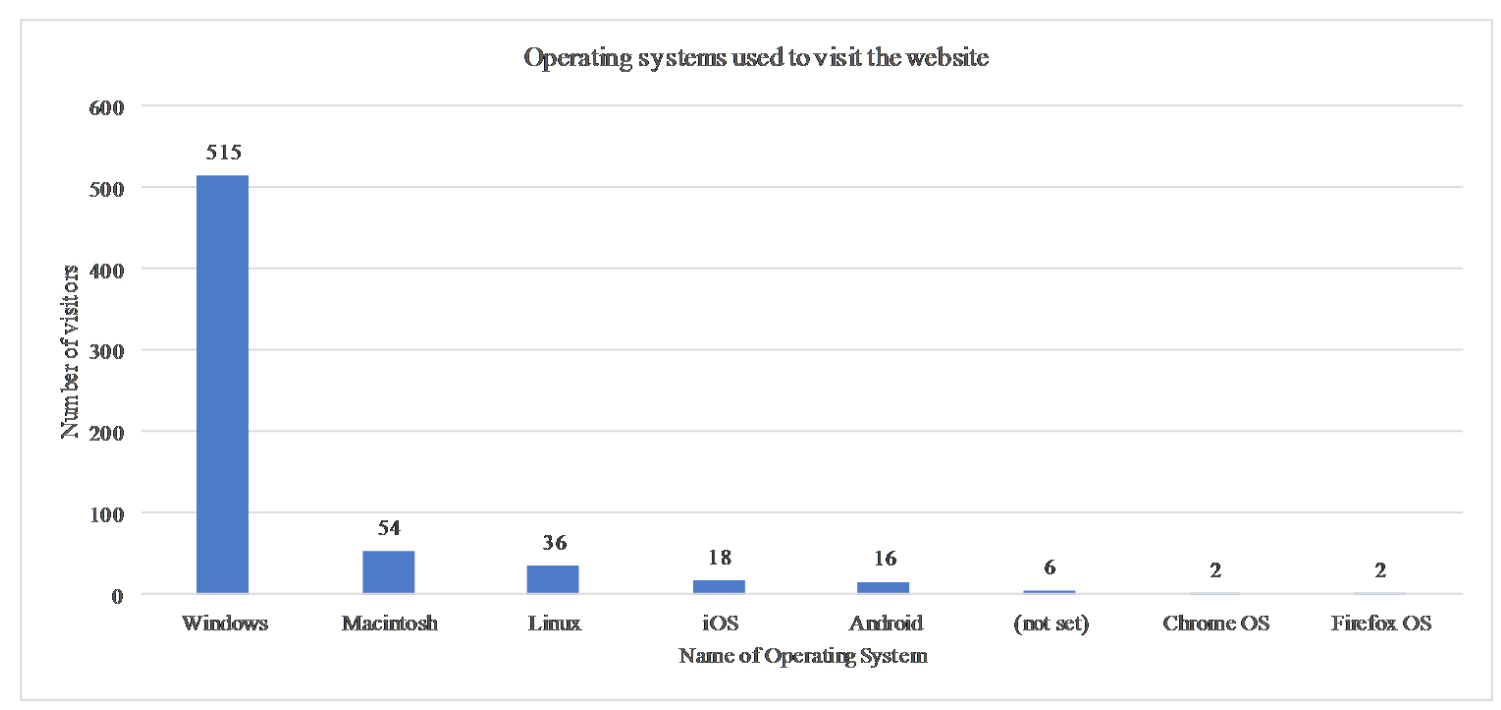

Figure 2: Frequency of operating systems used by knowledge repository visitors.

Figure 2 shows that $79 \%$ of knowledge repository visitors used Windows that positions the operating system (OS) as dominant and mostly used. The figure includes OS that are developed for mobile phones such as Android, Firefox and iOS. The revised plan for the knowledge repository will also incorporate a mobile-friendly interface as deferred action.

The leading browser used by knowledge repository visitors is Chrome with $58 \%$ followed by Firefox, $16 \%$, and Safari, $4 \%$. Each OS provides a browser that comes with the technology (default) and is used to access the Internet. The fact that Chrome and Firefox are used by nearly $74 \%$ of the knowledge repository visitors explains the deferred action from using the default browser in an OS due to the ease of use, speed and other usability features.

\subsection{Webpages that visitors accessed}

In total, the 734 knowledge repository visitors had a combined view of 5393 pages. Of the combined page views, 723 lasted only 10 seconds. On average, visitors spent four minutes and 26 seconds on the knowledge repository. The visitors came from different channels that are grouped as the referral, direction, organic searches and social media.

About $34 \%$ of knowledge repository visitors came directly to the knowledge repository because they knew the knowledge repository URL and typed it in the address bar or used bookmark. Direct visitors are said to have planned to visit the knowledge repository. $48 \%$ of the visitors arrived at the ICTD-X knowledge repository from another knowledge repository that required them to click on a link as a referral. There were seven per cent knowledge repository visitors arriving because of organic searches using search engines such as Google, Yahoo and MSN. Twelve visitors used social media as the source before arriving on the knowledge repository. Nine of these visitors used Facebook and three used Twitter. About $26 \%$ of the knowledge repository visitors started on the home page before accessing other pages. The second most accessed webpage is that of search results where knowledge repository visitors were looking for specific information. The third accessed webpage explained resources such as ICTD initiatives and researches, South African research papers, blogs and seminal paper that were shared by DI members. The fourth most accessed page offered information on events, conferences and workshops. occurring in Sub-Saharan Africa.

\section{DISCUSSION}

Considering our findings in terms of the theory of deferred action, our planned actions was that the target group would be researchers above the age of 40 years, using English as language and desktop computers as access devices. The emergent action is that the majority of the knowledge repository visitors were aged 25-34 years' old representing a younger generation than expected and some used other languages than English such as French, Italian, Portuguese and Slovak. The majority of the knowledge repository visitors population did use desktop computers, but mobile phones were more prevalent than expected. Notably, mobile devices surpassed desktop computers in Sub-Saharan Africa as explained by Kafyulilo [22] in his research on mobile phones as tools for teaching and learning among secondary schools in Tanzania. The deferred action necessitates the development of the mobile version for the knowledge repository as the demand is mainly from early career researchers with a preference for mobile technology. The usage pattern was planned for returning knowledge repository visitors. Our data shows an emergent action with only $14 \%$ of knowledge repository visitors returning. That raises questions about the usefulness and usability and suggest a deferred action in that we have to reconsider the knowledge repository usability, content and the focus. Furthermore, the fact that most visitors accessed the knowledge repository in months that coincide with conference submission deadline and conference dates shows an emergent action in that knowledge repository visitors were influenced by activities in the society and used the digital platform to acquire relevant information. 
Given the knowledge repository's focus on ICTD members in Sub-Saharan Africa, we decided to invite input from South African ICTD researchers on the content and offer recommendations of researchers and practitioners to be added on the platform. The emergent action was that only $27 \%$ of ICTD members completed questionnaires and offered limited information about practitioners to add on the platform. The low return rate was unexpected especially given the aim of connecting ICTD researchers in the country and fostering research collaboration in ICTD in Sub-Saharan Africa. Additionally, the large number of knowledge repository visitors that came through referral is an emergent action as it was not anticipated. Our findings are different to those by Buhalis \& Mamalakis [23] where social media, specifically Facebook, had an overwhelming $93.4 \%$ of social influence to website visitors for the hotel website in Greece in a study on social media return on investment impact. The deferred action for the knowledge repository will be the need to incorporate social media and other digital platforms on the revised knowledge repository plan.

The results demonstrate the usefulness of TDA as a conceptual structuring mechanism and most of the deferred action can be considered as general recommendations. This theory-building effort is significant as the lack of theory building has been a major criticism against ICTD and HCI for development research [24, 25].

\section{CONCLUSION}

This paper provides an improved understanding of the use and usefulness of an ICTD knowledge repository in South Africa in terms of the theory of deferred action through which we can link the planned, emergence and deferred actions. The most interesting and counterintuitive finding was the emergent action that many visitors were from countries outside Africa and the relatively low interest from African countries. The deferred action is the recognition of this opportunity to use a knowledge repository for connecting to ICTD stakeholders globally. However, the low retention rate suggests that more should be done to sustain the visitor's interest and that suggest content and usability analyses. Retention of ICTD researchers on the knowledge repository will foster not only research collaboration but the Ubuntu spirit of working together towards developing other researchers in the field. The research offers a theoretical contribution by validating the theory of deferred action through its application in an empirical setting, the digital platform, in a global South context.

The practical contribution is the lessons learned towards improving digital platforms for research collaboration. The limitations of the study include the use of a single knowledge repository that is not connected to ICTD researchers roles and responsibilities. The study was also limited by having received only 16 responses to the survey. Future research should include a usability evaluation of the knowledge repository as well as an investigation into the knowledge repository features and mechanisms triggering and sustaining global North-South research collaboration. The lack of recommendation for practitioners requires further investigation as it could indicate a lack of university-industry collaboration. A pertinent finding is that future research should investigate factors that will assist in linking South African ICTD researchers to those in other African countries.

\section{ACKNOWLEDGMENTS}

This paper is based on the research supported by the South African Research Chairs Initiative of the Department of Science and Technology and National Research Foundation of South Africa (Grant No. 98564).

\section{REFERENCES}

[1] J.R. Maluleka, O. B. Onyancha, and I. Ajiferuke, "Factors influencing research collaboration in LIS schools in South Africa," Scientometrics, vol. 107, no. 2, pp. 337-355, 2016.

[2] E. van den Hoven and J. Connell, "Joint doctoral supervision across countries: Changes, challenges and considerations," Emerg. Dir. Dr. Educ., vol. 6, pp. 259-280, 2016.

[3] G. Ko, N. Jiao, and K. Corser, "A transcultural journey: An ensemble of Canadian, Chinese, and Australian doctoral students experiences," Emerg. Perspect., vol. 3, no. 1, pp. 29-41, 2019.

[4] A. De Moor, "A community network ontology for participatory collaboration mapping: Towards collective impact," Information, vol. 9, no. 151, pp. 1-37, 2018.

[5] R. Cilliers and L. Kruger, "Ila Mo (Come in): The use of collaborative technologies to mediate collective meaning making," 2018, [Online]. Available: https://doi.org/ $10.1145 / 3283458.3283502$.

[6] A. C. Jones, E. Scanlon, and G. Clough, "Mobile learning: Two case studies of supporting inquiry learning in informal and semiformal settings," Comput. Educ., vol. 61, pp. 21-32, 2013.

[7] E. Kazan, C. Tan, and E. Lim, "Towards a framework of digital platform disruption: A comparative study of centralized \& decentralized digital payment providers," 2014.

[8] S. Roodt, C. de Villiers, and P. Joubert, "Collaborative learning for the net generation: Using social networks in an undergraduate course," Int. J. Innov. Digit. Econ., vol. 3, no. 3, pp. 14-27, 2012.

[9] D. Freshwater, G. Sherwood, and V. Drury, "International research collaboration: Issues, benefits and challenges of the global network," J. Res. Nurs., vol. 11, no. 4, pp. 295-303, 2006.

[10] C. Neylon, M. Willmers, and T. King, "Rethinking Impact: Applying Altmetrics to Southern African Research," Sch. Commun. Africa Program., pp. 1-20, 2013.

[11] M. Castells, The rise of the network society, 2nd ed. Cambridge: Wiley-Blackwell, 2011.

[12] S. B. Khoza, "Academics' 'why' of knowledge-building for the Fourth Industrial Revolution and COVID-19 era," Int. J. High. Educ., vol. 9, no. 6, p. 247, 2020.

[13] J. van Biljon, M. Marais, and M. Platz, "Digital platforms for research collaboration: Using design science in developing a South African open knowledge repository," Inf. Technol. Dev., vol. 23, no. 3, pp. 463-485, 2017.

[14] E. T. Straub, "Understanding technology adoption: Theory and future directions for informal learning," Rev. Educ. Res., vol. 79, no. 2, pp. 625-649, 2009.

[15] M. Platz and J. Van Biljon, "Design of an open ICT4D knowledge repository," 2015, doi: 10.1109/ISTAFRICA.2015.7190542.

[16] N. V. Patel, T. Eldabi, and T. M. Khan, "The theory of deferred action," J. Enterp. Inf. Manag., vol. 23, no. 4, pp. 521-537, 2010.

[17] N. V. Patel and A. Ghoneim, "Managing emergent knowledge through deferred action design principles: The case of ecommerce virtual teams," J. Enterp. Inf. Manag., vol. 24, no. 5, pp. 424-439, 2011.

[18] M. Turpin, "Assessing South African ICT4D research outputs: A journal review," South African Comput. J., vol. 30, no. 1, pp. 108-127, 2018.

[19] S. Lehong, J. van Biljon, and E. De Kock, "Knowledge sharing platforms in ICT4D: Towards validated content requirements," in2018 Conference on Information Communications Technology and Society, ICTAS, 2018, pp. 1-6.

[20] J. W. Creswell, Research design: Qualitative, quantitative, and mixed methods approaches, 4th ed. Los Angeles: Sage publications, 2013.

[21] H. F. Hsieh and S. E. Shannon, "Three approaches to qualitative content analysis," Qual. Health Res., vol. 15, no. 9, pp. 1277-1288, 2005.

[22] A. Kafyulilo, "Access, use and perceptions of teachers and students towards mobile phones as a tool for teaching and learning in Tanzania," Educ. Inf. Technol., vol. 19 , no. 1 , pp. $115-127,2014$

[23] D. Buhalis and E. Mamalakis, "Social media return on investment and performance evaluation in the hotel industry context," Inf. Commun. Technol. Tour., pp. 241$253,2015$.

[24] N. Winters, \& K. Toyama (2009). Human-computer interaction for development: mapping the terrain. Information Technologies \& International Development, 5 (4), iii-viii.

[25] Best, M. L. (2010). Understanding Our Knowledge Gaps: Or, Do We Have an ICT4D Field? And Do We Want One? Information Technologies \& International Development, 6, 49-52. 